\title{
The Concerted Action of E2-2 and HEB Is Critical for Early Lymphoid Specification
}

\begin{abstract}
Thibault Bouderlique ${ }^{1 \dagger}$, Lucia Peña-Pérez ${ }^{1+}$, Shabnam Kharazi ${ }^{1}$, Miriam Hils ${ }^{2}$, Xiaoze $\mathrm{Li}^{1}$, Aleksandra Krstic ${ }^{1}$, Ayla De Paepe ${ }^{1}$, Christian Schachtrup ${ }^{3}$, Charlotte Gustafsson ${ }^{1}$, Dan Holmberg ${ }^{4}$, Kristina Schachtrup ${ }^{2}$ and Robert Månsson ${ }^{1,5 *}$

${ }^{1}$ Department of Laboratory Medicine, Center for Hematology and Regenerative Medicine, Karolinska Institutet, Stockholm, Sweden, ${ }^{2}$ Faculty of Medicine \& Faculty of Biology, Center for Chronic Immunodeficiency, Medical Center, University of Freiburg, Freiburg, Germany, ${ }^{3}$ Faculty of Medicine, Institute of Anatomy and Cell Biology, University of Freiburg, Freiburg, Germany, ${ }^{4}$ Lund University Diabetes Center, Lund University, Malmö, Sweden, ${ }^{5}$ Hematology Center, Karolinska University Hospital, Stockholm, Sweden
\end{abstract}

\section{OPEN ACCESS}

Edited by:

Barbara L. Kee,

University of Chicago, United States

Reviewed by:

Michele Kay Anderson,

University of Toronto, Canada

Rachel Maurie Gerstein,

University of Massachusetts Medical

School, United States

*Correspondence:

Robert Månsson

robert.mansson@ki.se

†These authors have contributed equally to this work

Specialty section: This article was submitted to B Cell Biology,

a section of the journal

Frontiers in Immunology

Received: 14 December 2018 Accepted: 20 February 2019 Published: 18 March 2019

Citation:

Bouderlique T, Peña-Pérez L, Kharazi S, Hils M, LiX, Krstic A, De Paepe A, Schachtrup C,

Gustafsson C, Holmberg $D$

Schachtrup K and Månsson R (2019)

The Concerted Action of E2-2 and

HEB Is Critical for Early Lymphoid

Specification. Front. Immunol. 10:455.

doi: 10.3389/fimmu.2019.00455
The apparition of adaptive immunity in Gnathostomata correlates with the expansion of the E-protein family to encompass E2-2, HEB, and E2A. Within the family, E2-2 and HEB are more closely evolutionarily related but their concerted action in hematopoiesis remains to be explored. Here we show that the combined disruption of E2-2 and HEB results in failure to express the early lymphoid program in Common lymphoid precursors (CLPS) and a near complete block in B-cell development. In the thymus, Early T-cell progenitors (ETPS) were reduced and T-cell development perturbed, resulting in reduced CD4 T- and increased $\gamma \delta$ T-cell numbers. In contrast, hematopoietic stem cells (HSCs), erythro-myeloid progenitors, and innate immune cells were unaffected showing that E2-2 and HEB are dispensable for the ancestral hematopoietic lineages. Taken together, this E-protein dependence suggests that the appearance of the full Gnathostomata E-protein repertoire was critical to reinforce the gene regulatory circuits that drove the emergence and expansion of the lineages constituting humoral immunity.

Keywords: E-protein, lymphoid specification, hematopoiesis, humoral immunity, evolution

Large Eumetazoan rely on an efficient system of innate and adaptive immune cells to survive and reach reproductive age (1-3). The different cells of the hematopoietic system are all generated from hematopoietic stem cells (HSCs) (4). Lymphoid specification is initiated in lymphoid primed multipotent progenitors (LMPPs) that start to express genes associated with adaptive immune cells $(5,6)$. LMPPs subsequently give rise to common lymphoid precursors (CLP) (7). Within the heterogeneous CLP population, the $\mathrm{LY} \mathrm{D}^{+}$fraction is further specified toward a B-lineage fate $(8,9)$ and contains the first B-lineage committed cells that subsequently give rise to mature B-cells $(9,10)$. Early lymphoid precursors leave the bone marrow to seed the thymus where they further develop into early T-cell progenitors (ETP) that give rise to mature T-cells (11). Similarly, the innate immune cells develop from different progenitors within the myeloid branch $(12,13)$, while natural killer (NK) cells and part of the dendritic cells (DC) develop from the CLP $(7,14)$.

The origin of the Gnathostomata (jawed vertebrate) hematopoietic system can be traced far back in evolutionary history with phagocytic and cytotoxic innate immune cells being found across the 
Bilateria (15) and the erythroid/megakaryocyte lineages appearing in the Agnatha (16). Similarly, lymphoid-like cells are present in the Agnatha (17), Urochordata (18), and Cephalochordata (19). However, while genes intimately associated with adaptive immunity-including RAG $(20,21)$, histocompatibility genes $(22,23)$, and immune type receptors $(22,24,25)$-are found in lower Deuterostomata, B- and T-cells mediated adaptive immunity emerged only in the Gnathostomata. The appearance of new transcription factor (TF) genes drive the apparition of novel cell types (26). The appearance of adaptive immunity in the Gnathostomata correlates with a dramatic increase in $\operatorname{TF}$ genes $(1,27)$. As part of this expansion, the full Gnathostomata basic helix-loop-helix E-protein family $(28,29)$ consisting of E2A (Tcf3), HEB (Tcf12), and E2-2 (Tcf4) emerged.

It has been proposed, that E2A is more closely related to the ancestral E-proteins while E2-2 and HEB are less evolutionarily conserved and display expression patterns more restricted to vertebrate-specific structures $(29,30)$. This suggests that E2A should govern ancestral functions while HEB and E2-2 should govern novel functions that emerged concomitantly to the rise of the Gnathostomata. In line with this, E2A is the only E-protein reported to impact HSC function and the development of the myeloid- and erythro/megakaryocytic lineages (31-35). In contrast, all the E-proteins promote development of B- and T-cells $(32,36-47)$. The potential role of E2-2 in stem- and progenitor cells remains largely unexplored.

Here we confirm that E2-2 and HEB are evolutionary related and we found that their coordinated action is critical for the development of early lymphoid progenitors. Mice lacking both E2-2 and HEB display an almost complete block in B-cell development at the level of the CLP and the few generated immature B-cells preferentially develop into marginal zone (MZ) B-cells. Similarly, we found T-cell development to be perturbed, resulting in reduced numbers of CD4 T-cells and increased numbers of $\gamma \delta$ T-cells. In contrast, HSCs, erythromyeloid development and the generation of innate immune cells were unperturbed. Together, this suggests that E2-2 and HEB are dispensable for ancestral hematopoietic lineages and that the appearance of the full Gnathostomata E-protein repertoire promoted the apparition of humoral immunity.

\section{MATERIALS AND METHODS}

\section{Animal Studies}

To generate mice lacking specific E-proteins in the hematopoietic system, Vav-iCre (48) was used in combination with conditional (floxed) E2-2 (49), HEB (44), and E2A (50) alleles. Mice were maintained on a C57BL/6 background and analyzed at 8-14 weeks of age. Animal studies were approved by the local ethics committee (ethical approval number S16-15).

\section{Preparation of Cells and Flow Cytometry}

Bones, spleen, and thymus were dissected, crushed in PBS with $2 \%$ FCS and cells were collected after passing through a $70 \mu \mathrm{m}$ filter. They were then Fc-blocked (CD16/32; 93) and stained with combinations of the antibodies Sca1 (D7), CD105 (MJ7/18),
CD41 (MWReg30), CD48 (HM48-1), CD3 (145-2C11), CD4 (RM4-5), CD8 (53-6.7), B220 (RA3-6B2), NK1.1 (PK136), Mac1 (M1/70), Gr1 (RB6-8C5), TER119 (TER-119), CD150 (TCF1512F12.2), CD117 (2B8, eBioscience), CD127 (A7R34), CD44 (IM7), CD25 (PC61.5, eBioscience), CD19 (1D3, eBioscience), TcR $\beta$ (H57-597, eBioscience), TcR $\gamma \delta$ (GL3, eBioscience), Ly6C (AL-21), Ly6G (1A8), MHCII (M5/114.15.2), CD11c (N418), PDCA1 (927), Ly6D (49H4), Flt3 (A2F10), IgD (11-26c.2a), and $\operatorname{IgM}(11 / 41$, eBioscience). All antibodies were purchased from BD Biosciences unless otherwise indicated. Propidium iodide (PI) was utilized to discriminate dead cells. For hematopoietic stem and progenitor cell isolation, cells were subjected to lineage depletion using Dynabeads sheep anti rat IgG (Life Technologies) together with TER119, CD19, CD3, Gr1, and $\mathrm{CD} 11 \mathrm{~b}$ antibodies prior to staining. Analysis and cell sorting was performed primarily on an LSR Fortessa and FACSAria IIu (BD Biosciences). Analysis of data was done using the Flowjo 9.9.6 software (Flowjo).

\section{Phylogenetic Analysis}

The cDNA and amino acids sequences of the E-proteins from analyzed organisms were obtained through the E-ensembl repository (51). See Table $\mathbf{S} 1$ for the sequences used in this study. Phylogenetic trees were constructed with MEGA7 (52) selecting the Maximum Likelihood method based on the TamuraNei model; creating initial tree(s) using the Neighbor-Joining and BioNJ algorithms; and using a Gamma distribution with invariant sites. All positions in the cDNA and amino acids sequences (including gaps) were considered when constructing the trees. To assess the support of each node, the tree was bootstrapped 500 times.

\section{RNA Sequencing and Analysis}

$5-10 \times 10^{3}$ cells were FACS-sorted into buffer RLT with $\beta$-mercaptoethanol and total RNA extracted using RNeasy Micro Kit (Qiagen, Hilden, Germany) with on-column DNase I treatment. Strand specific RNAseq libraries were prepared using the TotalScript ${ }^{\mathrm{TM}}$ RNA-seq kit (Epicenter, Madison, WI) together with custom made Tn5 (transposase). Barcoded libraries were pooled and pair-end sequenced $(2 \times 50$ cycles $)$ using the Illumina platform (NextSeq500, Illumina, San Diego, CA).

RNAseq reads were mapped using STAR (53), reads in exons quantified using HOMER (54) and significant changes identified using EdgeR. Principal component analysis (PCA) analysis and display was performed using R (v3.3.3). For details see Supplemental Materials and Methods.

\section{Pro B Cell Expansion Cultures and Fixation}

$\mathrm{B} 220^{+}$cells were isolated from bone marrow of ER-Cre mice (55) using magnetic cell separation (Miltenyi Biotec), expanded for 6 days in the presence of IL-7 and SCF to obtain pro B-cells. Pro B-cells were subsequently retrovirally transduced with Bcl-2, expanded for seven additional days with $5 \mu \mathrm{M} 4$ Hydroxytamoxifen in the medium during the last $72 \mathrm{~h}$. Pro B-cells were fixed using EGS ( $1.5 \mathrm{mM}$ for $30 \mathrm{~min}$ ) in combination with PFA ( $1 \%$ for $10 \mathrm{~min}$ ) and stored as pellets in $-80^{\circ} \mathrm{C}$. 


\section{ChIP Sequencing and Analysis}

In brief, fixed pro B-cells were thawed, resuspended in SDS lysis buffer, sonicated, and lysates subjected to ChIP by adding dynabeads pre-loaded with either antibodies against E2A, HEB, or E2-2. ChIPed chromatin was washed and libraries prepared using reverse crosslinking in conjunction with adapter ligation using the ThruPLEX DNA-seq kit (Rubicon Genomics) or using the high-throughput ChIPmentation approach (tagmentation followed by direct amplification of libraries without prior DNA purification) (56). For details see Supplemental Materials and Methods. Libraries were sequenced using the HiSeq2000 or NextSeq500 platforms (Illumina).

ChIPseq reads were mapped using bowtie2 (57). Identification of peaks, peak overlaps and motif enrichment/identification analysis was done using HOMER's findPeaks, mergePeaks, and findMotifsGenome.pl, respectively (54). Visualization was done using the UCSC genome browser. For details see Supplemental Materials and Methods.

\section{RESULTS}

\section{E2-2 and HEB Are Evolutionarily Related}

To investigate the evolutionary history of the E-proteins in Bilateria in light of recent sequencing data, we analyzed similarities between CDNA and amino acid sequences of the Eproteins across Animalia (Figures S1A-D). The E-proteins of Protostomata and non-gnathostome Deuterostomata clustered together (Figure S1B) and displayed relatively high sequence divergence (Figure S1C) on the cDNA level. The Gnathostomata E-proteins, in contrast, formed a separate clade (Figure S1B) and displayed comparably higher similarity (Figure S1C). Within the Gnathostomata clade, E2-2, and HEB formed a separate branch from that of E2A (Figure S1B). Similar results were obtained from the analysis of the amino acid sequences (Figure S1D). This confirms the closer evolutionary relation between E2-2 and HEB in Gnathostomata $(29,58)$. It could hence be hypothesized that E2-2 and HEB are functionally related and together support the development of cell lineages specific to the jawed vertebrate hematopoietic system.

\section{Deletion of E2-2 and HEB Does Not Impact HSCs and Erythro-Myeloid Progenitors}

To investigate the role of E2-2 and HEB in hematopoiesis, we used the $\mathrm{Vav}^{\mathrm{iCre}}$ mouse strain to mediate conditional deletion of E2-2 (E2-2 $\left.{ }^{\mathrm{f} / \mathrm{f}} \mathrm{Vav}^{\mathrm{iCre}}\right)$ or E2-2 together with HEB (E2$\left.{ }^{\mathrm{f} / \mathrm{f}} \mathrm{HEB}^{\mathrm{f} / \mathrm{f}} \mathrm{Vav}^{\mathrm{iCre}}\right)$ in the hematopoietic system. Cre mediated deletion of the floxed exons was verified in RNAseq data from FACS sorted cells (Figures S2A-C). We observed a difference in bone marrow (BM) cellularity only between littermate control mice (lacking $\mathrm{Vav}^{\mathrm{iCre}}$ ) and $\mathrm{E} 2-2^{\mathrm{f} / \mathrm{f}} \mathrm{HEB}^{\mathrm{f} / \mathrm{f}} \mathrm{Vav}^{\mathrm{iCre}}$ mice (Figure 1A). However, no differences were observed in the number of HSCs (Figure 1B, Figure S3A), megakaryocyte, erythroid, and myeloid progenitors (Figure 1C, Figure S3B). While being expressed in the HSC and erythro-myeloid progenitors (Figure S2D), E2-2 and HEB are hence dispensable for the maintenance and generation of these cell types in steady state (32). This leaves E2A as the sole E-protein needed for HSCs and erythro-myeloid development (31).

\section{Generation of Innate Immune Cells Except pDCs Are Unaffected by E2-2 and HEB Deletion}

While the total number of spleen cells was reduced in E2$2^{\mathrm{f} / \mathrm{f}} \mathrm{HEB}^{\mathrm{f} / \mathrm{f}} \mathrm{Vav}^{\mathrm{iCre}}$ mice (Figure 1D), no effect was observed on the number of mature myeloid cells (Figure 1E, Figure S3C). This further support that E2-2 and HEB are dispensable for myelopoiesis. Similarly, natural killer (NK) cell numbers were unaffected (Figure 1E, Figure S3C). In contrast, plasmacytoid dendritic cells (pDC) were reduced by $86 \%$ by the deletion of E22 and by $98 \%$ with the additional removal of HEB (Figures 1F,G) indicating a previously unrecognized dependence on HEB for pDC development (59).

\section{E2-2 and HEB Are Needed for Proper Generation of B-Cells and CD4 T-Cells}

As the total number of spleen cells was reduced (Figure 1D), we next investigated the effect of deletion of E2-2 and HEB on the adaptive immune cells. The number of T-cells in the spleen was not impacted by the depletion of E2-2, but E2-2 $2^{\mathrm{f} / \mathrm{f}} \mathrm{HEB}^{\mathrm{f} / \mathrm{f}} \mathrm{Vav}$ iCre mice displayed a $60 \%$ reduction in CD4 T-cells (Figure 2A). The total number of B-cells in spleen was reduced by $42 \%$ by the deletion of E2-2 and by $68 \%$ when HEB was additionally depleted (Figure 2B). This reduction reflected a sharp drop in transitional- and follicular B-cells $(\mathrm{FoB})$ while marginal zone (MZ) B-cell numbers remained unaffected in $\mathrm{E} 2-2^{\mathrm{f} / \mathrm{f}} \mathrm{Vav}$-iCre and increased in $\mathrm{E}^{2}-2^{\mathrm{f} / \mathrm{f}} \mathrm{HEB}^{\mathrm{f} / \mathrm{f}}$ Vav-iCre mice (Figures $2 \mathrm{C}-\mathrm{E}$ ). This suggests that the removal of E2-2 and HEB heavily promoted the generation of $\mathrm{MZ}$ from transitional B-cells at the expense of FoB $(60,61)$. Taken together, these data show that cell lineages with ancestral functions (erythro-myeloid and cytotoxic cells) $(15,16,62-65)$ are independent of E2-2 and HEB. In contrast, cell lineages central to adaptive (humoral) immunity (B- and CD4 Tcells) or at the interphase between innate and adaptive immunity (pDC) are dependent on E2-2 and/or HEB.

\section{The Development of CD4 and $\gamma \delta$ T-Cells Is Perturbed by the Loss of E2-2 and HEB}

With $\mathrm{E} 2-2^{\mathrm{f} / \mathrm{f}} \mathrm{HEB}^{\mathrm{f} / \mathrm{f}} \mathrm{Vav}^{\mathrm{iCre}}$ mice displaying decreased $\mathrm{CD} 4$ T-cells in the periphery (Figure 2A), we next investigated T-cell development in the thymus (Figure 3A). Depletion of E2-2 had no effect on thymic cellularity (Figure 3B). However, E2-2 ${ }^{\mathrm{f} / \mathrm{f}} \mathrm{Vav}^{\mathrm{iCre}}$ mice displayed a visible decrease in ETPs and DN2 followed by decreases in DN3E and IS(8)P (Figure 3D). In line with previous studies of HEB knockout animals (36), the additional deletion of HEB perturbed T-cell development (Figure 3A) with decreased total cellularity in thymus (Figure 3B); significant decreases in ETP and DN2 (Figure 3C); increases in DN3E, DN3L, and IS(8)P (Figure 3D); but markedly reduced DPs (Figure 3D). In spite of the marked reduction in DPs, CD8 T-cells were present in normal numbers (Figure 3E) while CD4 T-cells were severely reduced (>85\%). 

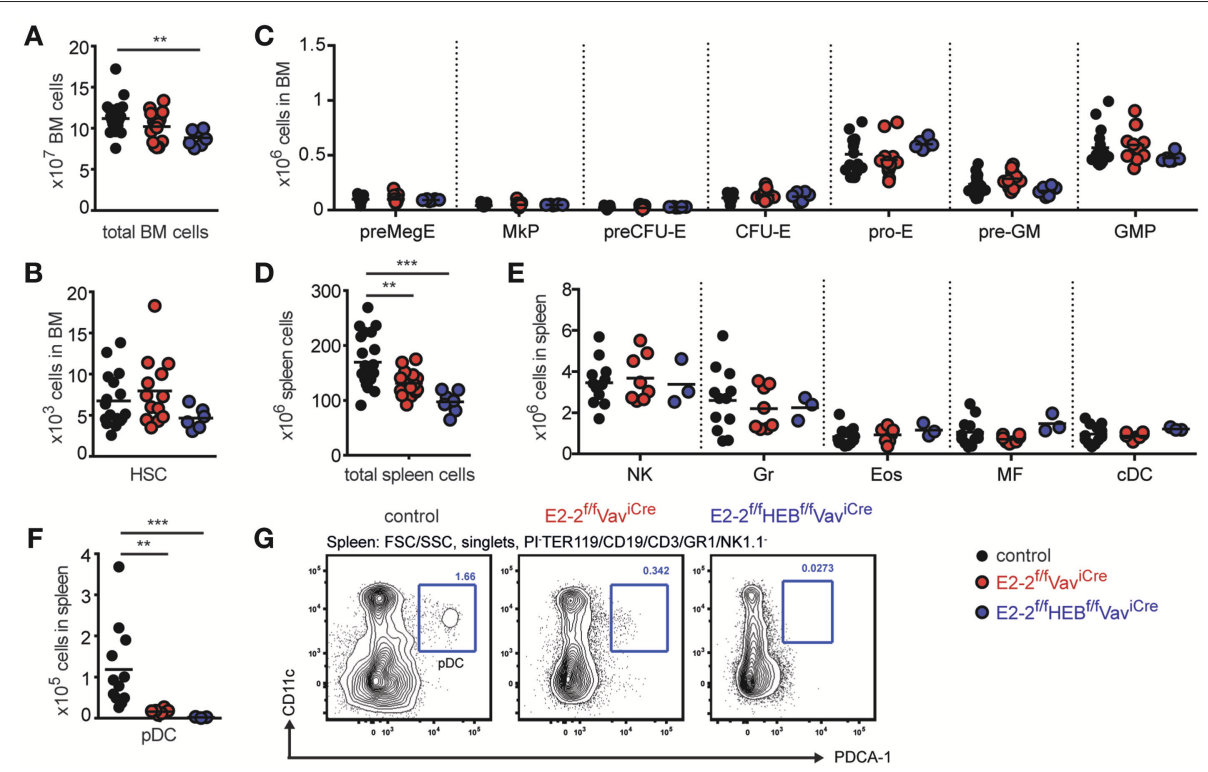

- control

- E2-2 $2^{\mathrm{f} / \mathrm{V}}$ Vavicre

- E2-2 ${ }^{\mathrm{f} / \mathrm{H}} \mathrm{HEB}^{\mathrm{f} / \mathrm{V}} \mathrm{Vav}^{\mathrm{iCre}}$

FIGURE 1 | E2-2 and HEB are dispensable for ancestral lineages. Absolute number of total cells (A), hematopoietic stem cells (HSCs) (B), and erythro-myeloid progenitors (C) in bone marrow. Absolute number of total cells (D), innate immune cells (E) (Gr, granulocytes; Eos, eosinophiles; MF, macrophages; cDC, conventional dendritic cells) and plasmacytoid dendritic cells (pDC) (F) in spleen. For gating strategies for cell types in panel E-F and H see Figures S3A-C. (G) Gating strategy for identification of pDCs. Prior gating is indicated above the FACS plots. Color symbols utilized throughout the figure to indicate the genotype of analyzed mice are shown in the bottom right corner. Significance was calculated using the Mann-Whitney $U$ test with ${ }^{* *}$ and ${ }^{* \star *}$ indicating $p$-values $<0.01$ and $<0.001$, respectively.

Additionally, E2-2 ${ }^{\mathrm{f} / \mathrm{f}} \mathrm{HEB}^{\mathrm{f} / \mathrm{f}} \operatorname{Vav}^{\mathrm{iCre}}$ animals displayed markedly increased (6-fold) $\gamma \delta$ T-cells numbers (Figure 3E) $(36,66)$.

Looking closer at the progressive generation of cells from the prior stage in each developmental transition in E2$2^{\mathrm{f} / \mathrm{f}} \mathrm{HEB}^{\mathrm{f} / \mathrm{f}} \operatorname{Vav}^{\text {iCre }}$ mice, the altered cell numbers observed were mirrored by increased generation of DN3E, DN3L, and IS(8)P before a sharp drop in the generation of DP TCR $\beta^{-}$cells (Figure 3F). While few in numbers, DP TCR $\beta^{+}$were generated in increased numbers with CD4 and CD8 T-cells subsequently being generated at a normal and increased ratio, respectively (Figure 3F). Taken together these results demonstrate that E2-2 and HEB are needed for normal thymopoiesis.

\section{E2-2 and HEB Are Critical for Lymphoid Specification and B-Cell Development}

The development of LMPPs and CLPs constitute the first steps of lymphoid specification $(5,7,9)$. Depletion of E2-2 alone did not significantly affect the number of LMPPs and Ly6D ${ }^{-}$CLPs (Figures 4A-C). However, the number of B-cell specified LY6D ${ }^{+}$CLPs $(8,9)$ was reduced by half (Figure 4C). Correspondingly, total B-cells were reduced by 43\% (Figure 4D) with each stage in B-cell development displaying a 30-50\% reduction (Figures 4E,F). The additional loss of HEB, in contrast, lead to a 70\% decrease in the number of LMPPs and LY6D ${ }^{-}$CLP (Figures 4A-C). In addition, the $\mathrm{E} 2-2^{\mathrm{f} / \mathrm{f}} \mathrm{HEB}^{\mathrm{f} / \mathrm{f}} \mathrm{Vav}^{\mathrm{iCre}}$ mice strikingly displayed a near complete loss of LY6D ${ }^{+}$CLP (>98\% reduction) (Figures 4A,B). This phenotype is similar to what has previously been reported for E2A knock-out (32). Accordingly, B-cell numbers were severely reduced (Figure 4D) with a $>99 \%$ reduction in cell-numbers of maturing B-cells (Figures $4 \mathrm{E}, \mathrm{F}$ ) and a $94 \%$ reduction in mature B-cells (Figures $4 \mathrm{E}, \mathrm{F}$ ) in BM.

To analyze more closely the impact of E2-2 and HEB depletion on developmental transitions, we plotted cell number ratios at each consecutive stage of development as a fraction of the prior stage (Figure 4G). E2-2 deficient mice only displayed a modest decrease in the generation of $\mathrm{LY}^{+} \mathrm{D}^{+} \mathrm{CLP}$ from $\mathrm{LY}^{-} \mathrm{CLP}$ while the consecutive generation of $\mathrm{CD}^{+} 9^{+}$developmental stages remained unaffected (Figure 4G). This indicates that E22, similarly to what has been reported for HEB deficient animals (32), is important for the $\mathrm{LY}^{-} \mathrm{D}^{-}$to $\mathrm{LY}^{+} \mathrm{D}^{+}$CLP transition but largely dispensable for BM B-cell maturation. This is in line with the expression data showing that early lymphoid progenitors (LMPPs and CLPs) expressed similar levels of E2-2, HEB and E2A while HEB and E2A were the predominantly expressed Eproteins in B-lineage cells (Figure S2D). The combined deletion of E2-2 and HEB severely impacted the generation of LMPPs, LY $6 \mathrm{D}^{+} \mathrm{CLP}$ and pre-B while, at the same time, seemingly increasing the generation of immature B-cells (Figure 4G). Interestingly, the generation of proB cells from the few remaining LY6D ${ }^{+}$CLP was unaffected (Figure 4G), indicating that Blineage commitment at this stage is unperturbed by the lack of E2-2 and HEB. Together, this demonstrates that the collaboration of E2-2 and HEB is critical for the generation of early lymphoid progenitors and the development of B-cells in the BM.

\section{Expression of the Early Lymphoid Program Is Disrupted by Removal of E2-2 and HEB}

To better understand the mechanisms behind the impaired generation of the B-cell specified LY6D ${ }^{+}$CLPs and to understand 

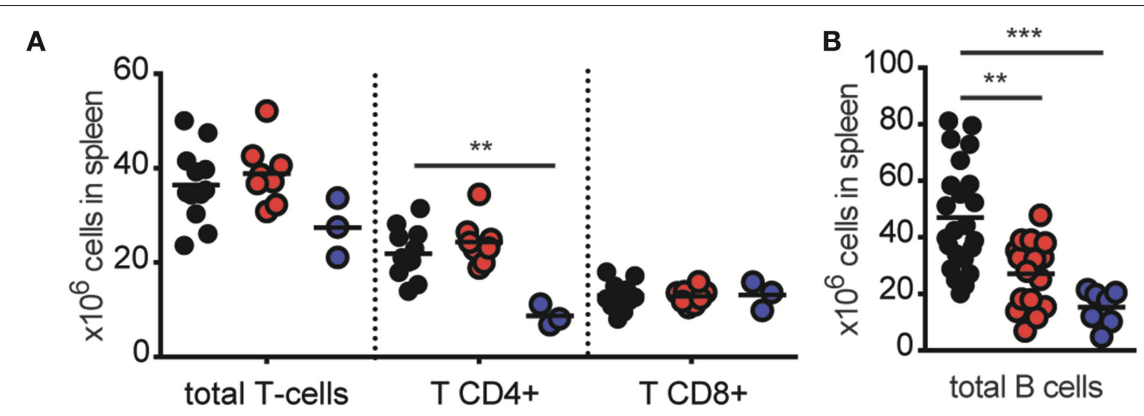

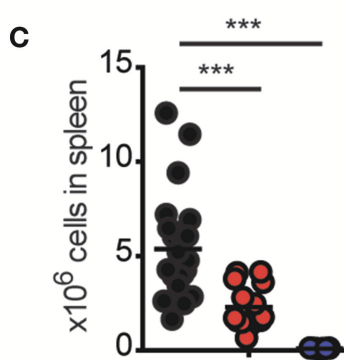

T1

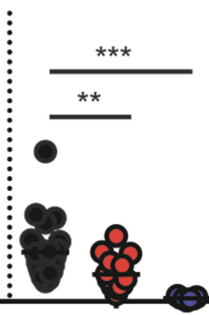

$\mathrm{T} 2$

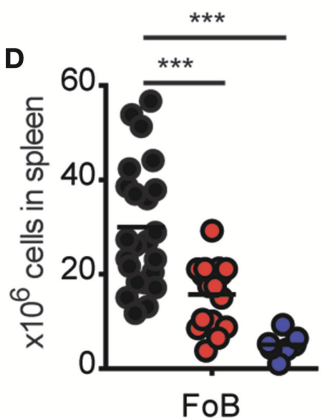

$\mathrm{MZ}$

FoB

E

- control

- E2-2 $2^{\mathrm{f} / \mathrm{V}} \operatorname{Vav}^{\mathrm{i}} \mathrm{Cre}$

- E2-2 $2^{\mathrm{f} / \mathrm{f}} \mathrm{HEB}^{\mathrm{f} / \mathrm{V}}$ Vav ${ }^{\mathrm{iCre}}$

Spleen: FSC/SSC, singlets, PI- GR1/MAC1/TER119/CD3e/NK1.1'10w/ CD19+
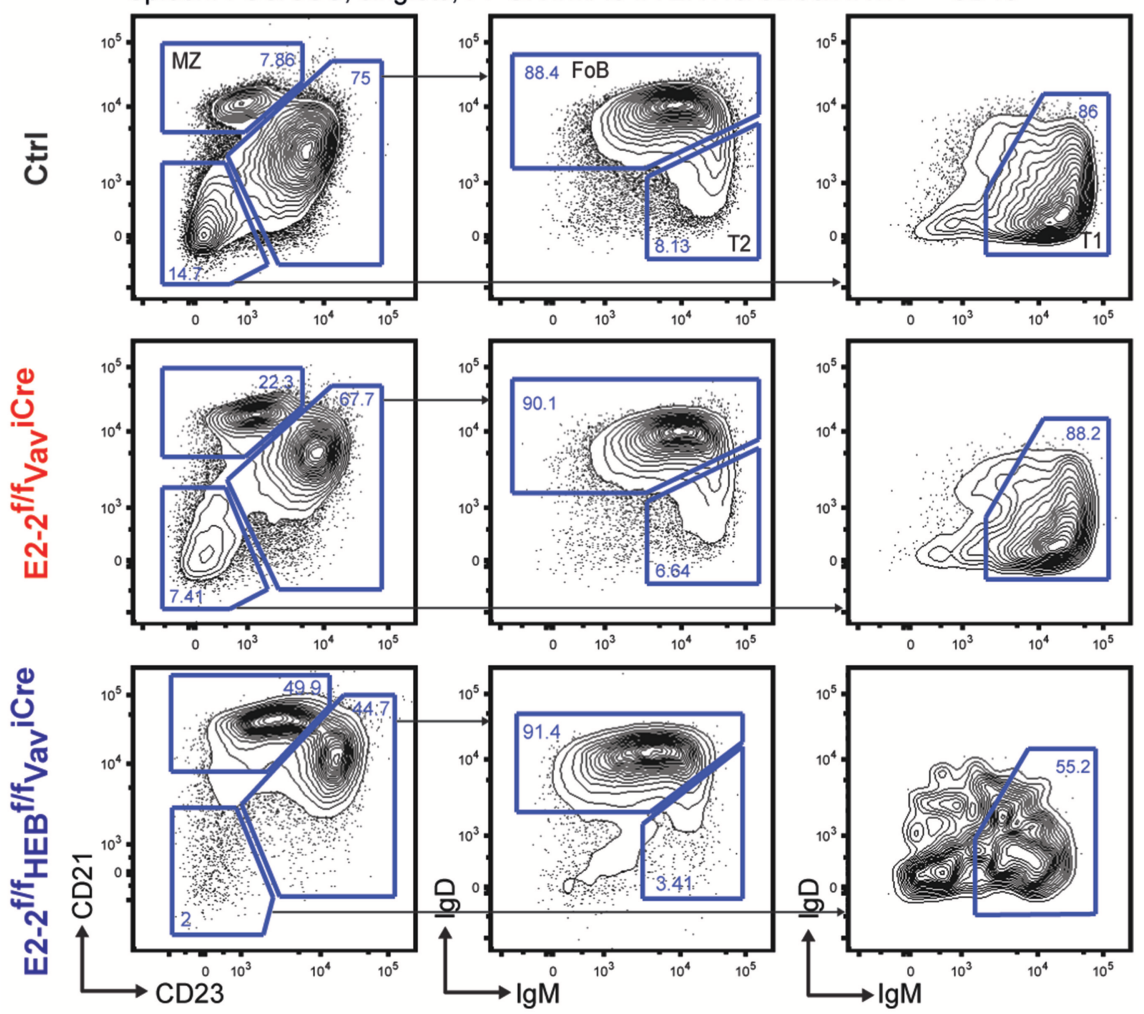

FIGURE 2 | E2-2 and HEB are needed for proper B-cell and CD4 T-cell generation. (A) Absolute number of T-cells, CD4 T-cells, and CD8 T-cells in spleen. For T-cell gating strategy see Figure S3C. Absolute number of B-cells (B) and B-cell subsets (C,D) (including: T1, transitional 1-, transitional 2-; MZ, marginal zone; and FoB, follicular B-cells) in spleen. (E) Gating strategy for identification of B-cell subsets. Prior gating is indicated above the FACS plots. Color symbols utilized throughout the figure to indicate the genotype of analyzed mice are shown below panels (C,D). Significance was calculated using the Mann-Whitney $U$ test with *, **, and *** indicating $p$-values $<0.05,<0.01$, and $<0.001$, respectively. 
A

Thymus: FSC/SSC, singlets, Pl CD19/B220'GR1/MAC1/TER119/NK1. $1^{\text {lowl. }}$
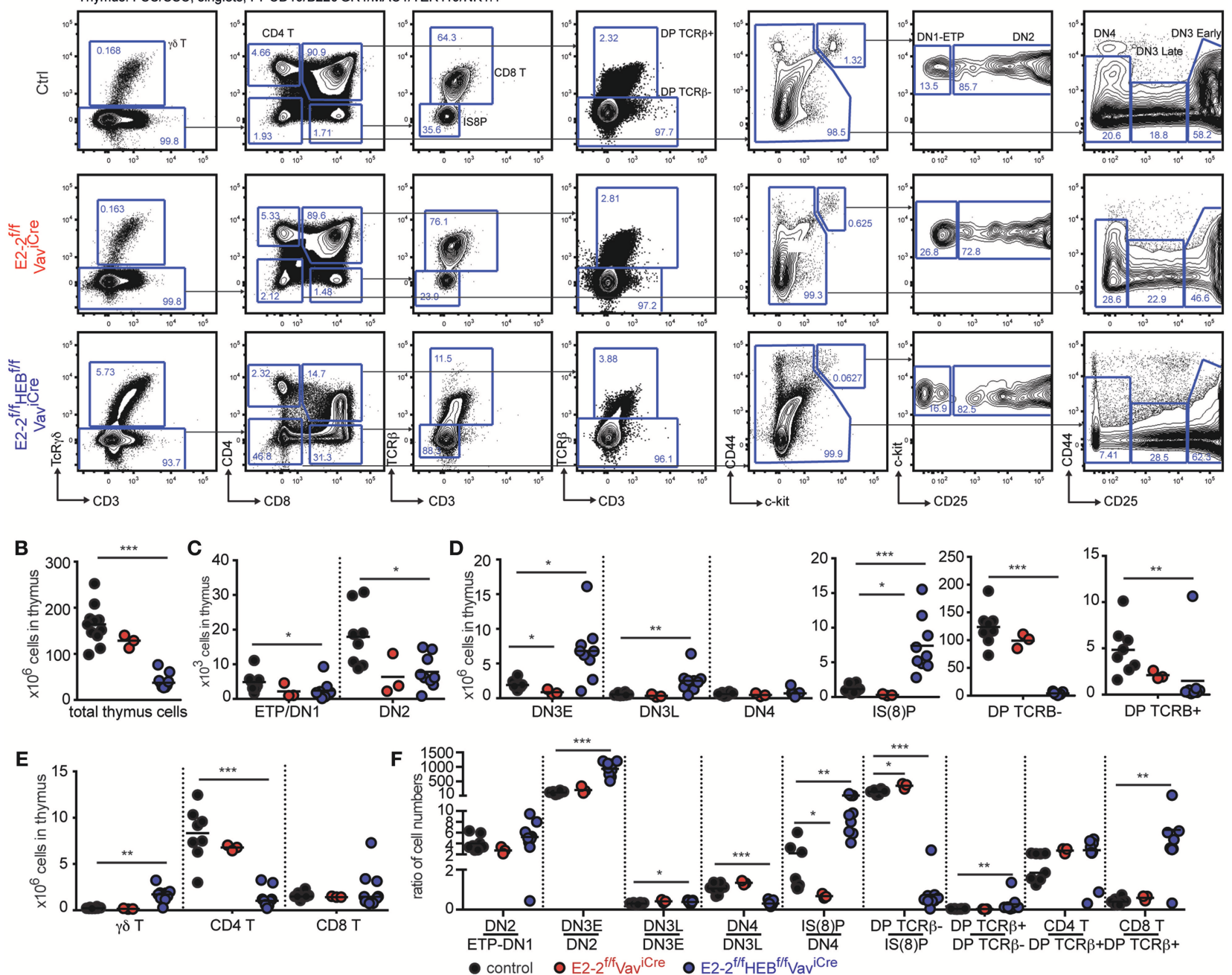

FIGURE 3 | Maturation of CD4 and $\gamma \delta$ T-cells is perturbed by the loss of E2-2 and HEB. (A) Gating strategy for identification of T-cell developmental stages. Absolute numbers of: total cells (B); ETP/DN1 and DN2 (C); DN3E, DN3L, DN4, IS(8)P, DP TCR $\beta^{-}$, and DP TCR $\beta^{+}$(D); and $\gamma \delta$ T-, CD4 T- and CD8 T-cells (E) in thymus. Prior gating is indicated above the FACS plots. (F) Cell number ratios for each consecutive stage of development as a fraction of the prior stage. Each dot represents the ratio for one individual animal. Color symbols utilized throughout the figure to indicate the genotype of analyzed mice are shown at the bottom of the figure.

Significance was calculated using the Mann-Whitney $U$ test with ${ }^{*}$, ${ }^{* *}$, and ${ }^{* * *}$ indicating $p$-values $<0.05,<0.01$, and $<0.001$ respectively.

how it relates to the similar phenotype observed in mice lacking E2A (32), we characterized the transcriptional profiles of LY6D ${ }^{-}$CLPs remaining in E2-2 ${ }^{\mathrm{f} / \mathrm{f}} \operatorname{Vav}^{\mathrm{iCre}}, \mathrm{E} 2-2^{\mathrm{f} / \mathrm{f}} \mathrm{HEB}^{\mathrm{f} / \mathrm{f}} \mathrm{Vav}^{\mathrm{iCre}}$, and $\mathrm{E} 2 \mathrm{~A}^{\mathrm{f} / \mathrm{f}}$ Vav $^{\mathrm{iCre}}$ mice using RNAseq (see Table $\mathbf{S} 2$ for sample information). Principal component analysis (PCA) of full

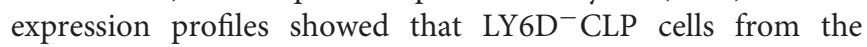
different genotypes form a distinct cluster and hence represent the same population of cells regardless of disrupted E-protein gene(s) (Figure 5A). A total of 150 genes displayed significant (corrected $p$-value $<0.01$ ) expression changes in LY6D ${ }^{-}$CLPs in one or more of the analyzed strains (Figure 5B). As expected, B-lineage related genes (including Ebf1, Blnk, Blk, Ets1, Dntt, Notch1, Rag1, and Rag2) were severely affected (Figure 5B) and overall the gene set was functionally associated with lymphocyte differentiation and signaling (Figure S4). While the majority of genes did not show highly significant changes in all genotypes (Figures 5C,D), the overall pattern of the expression changes was highly similar in $\mathrm{E} 2-2{ }^{\mathrm{ff}} \mathrm{HEB}^{\mathrm{ff}} \mathrm{Vav}^{\mathrm{iCre}}$ and $\mathrm{E} 2 \mathrm{~A}^{\mathrm{ff}} \mathrm{Vav}^{\mathrm{iCre}}$ mice (Figures 5B,D,E). The modest expression changes observed in the E2-2 ${ }^{\mathrm{ff}} \mathrm{Vav}{ }^{\mathrm{iCre}}$ mice were often concordant to those observed in $\mathrm{E}_{2} \mathrm{~A}^{\mathrm{ff}} \mathrm{Vav}{ }^{\mathrm{iCre}}$ mice and $\mathrm{E} 2-{ }^{\mathrm{ff}} \mathrm{HEB}^{\mathrm{ff}} \mathrm{Vav}^{\mathrm{iCre}}$ mice (Figures 5B,D,E). Taken together, this shows that E2-2, HEB and E2A largely reinforce the same gene network in early lymphoid progenitors while having variable impact on the expression of individual genes.

\section{E-proteins Display Partly Overlapping Association With Chromatin}

To further understand the mechanisms through which E2-2 and HEB control B lymphopoiesis, we analyzed the binding 

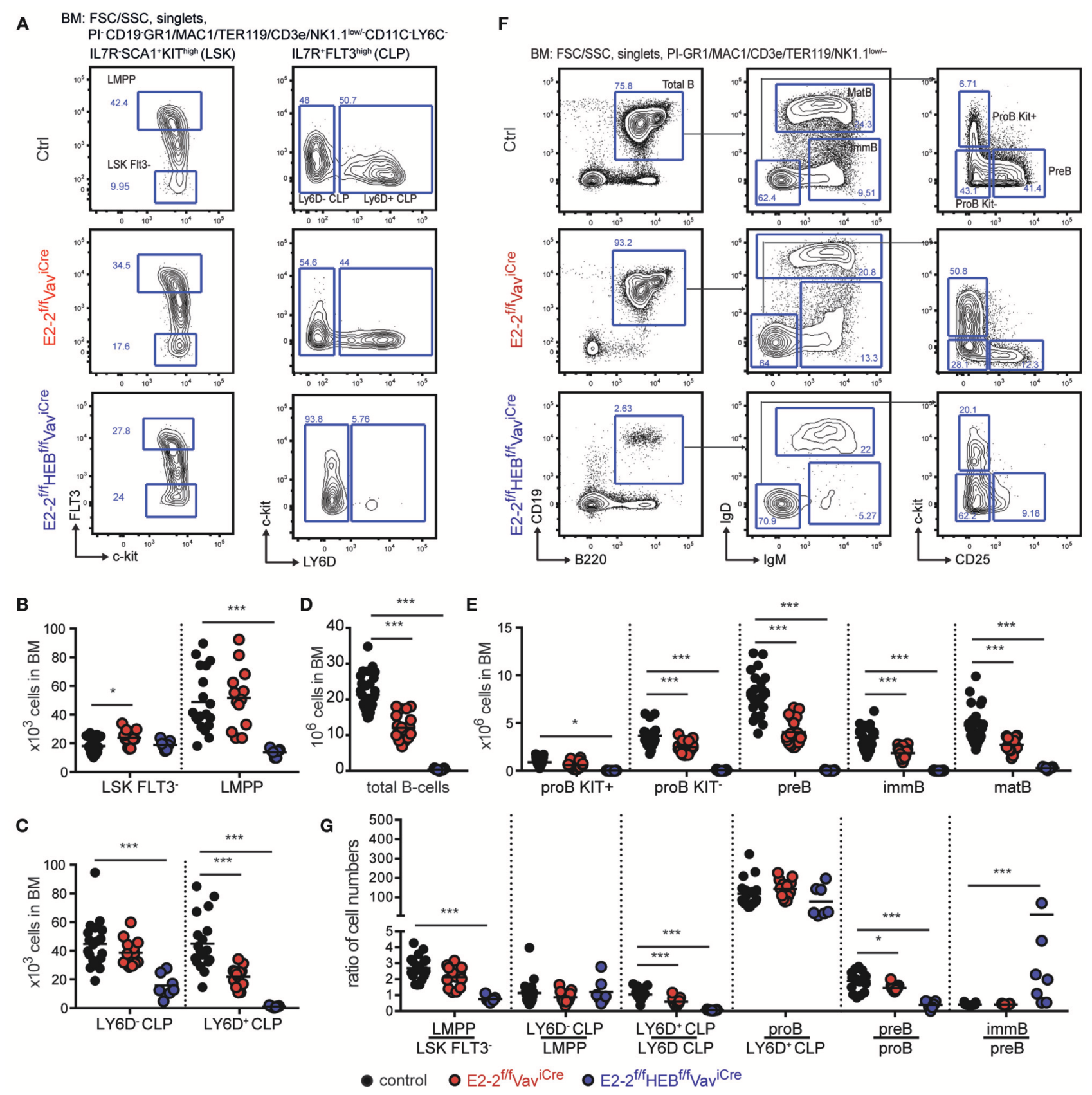

FIGURE 4 | The combined activity of E2-2 and HEB are critical for the generation of lymphoid progenitors and B-lineage cells. (A) Gating strategy for identification of stem- and lymphoid progenitors. Prior gating is indicated above the FACS plots. (B,C) Absolute numbers of stem- and lymphoid progenitors indicated cell types in BM. Absolute numbers of total B-cells (D) and each B-cell developmental stage (E) in BM. (F) Gating strategy for identification of total B-cells and B-cell developmental stages. Prior gating is indicated above the FACS plots. (G) Cell number ratios for each consecutive stage of development as a fraction of the prior stage. Each dot represents the ratio in an individual animal. Color symbols utilized throughout the figure to indicate the genotype of analyzed mice are shown below panel G. Significance was calculated using the Mann-Whitney $U$ test with * and *** indicating $p$-values $<0.05$ and $<0.001$ respectively.

pattern of E2A, HEB and E2-2 in pro B-cells using ChIP-seq in conjunction with adapter ligation (E2A) or high-throughput ChIPmentation (56) (HEB and E2-2) (see Table S2 for sample information). Library preparation using adapter ligation and tagmentation (ChIPmentation) has previously been shown to produce highly comparable results (67). We identified 16510 E2A, $2167 \mathrm{HEB}$ and 139 E2-2 high quality peaks (peak score $\geq 10$ ) (Figure 6A, Figure S5A). E2-2 is the lowest expressed E-protein in pro B-cells (Figure S2D) and the relatively low enrichment of E2-2 (most peaks have a peak score $<10$, 
A

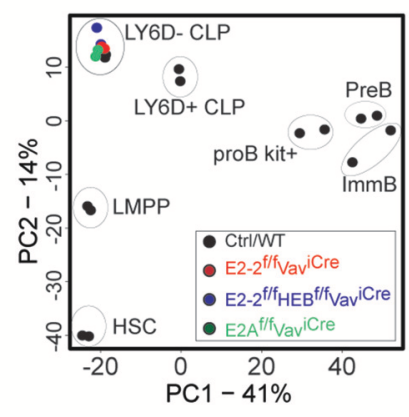

c

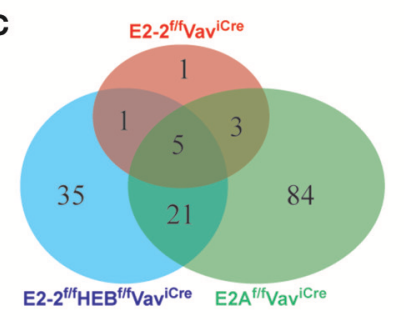

D

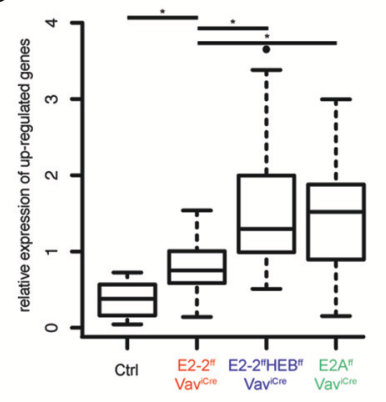

E

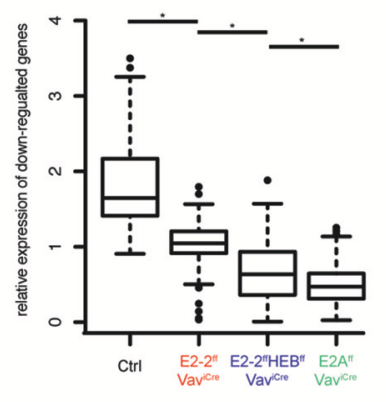

B

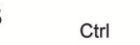

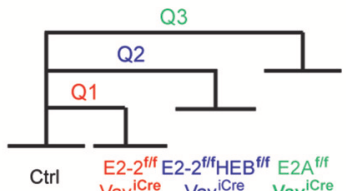
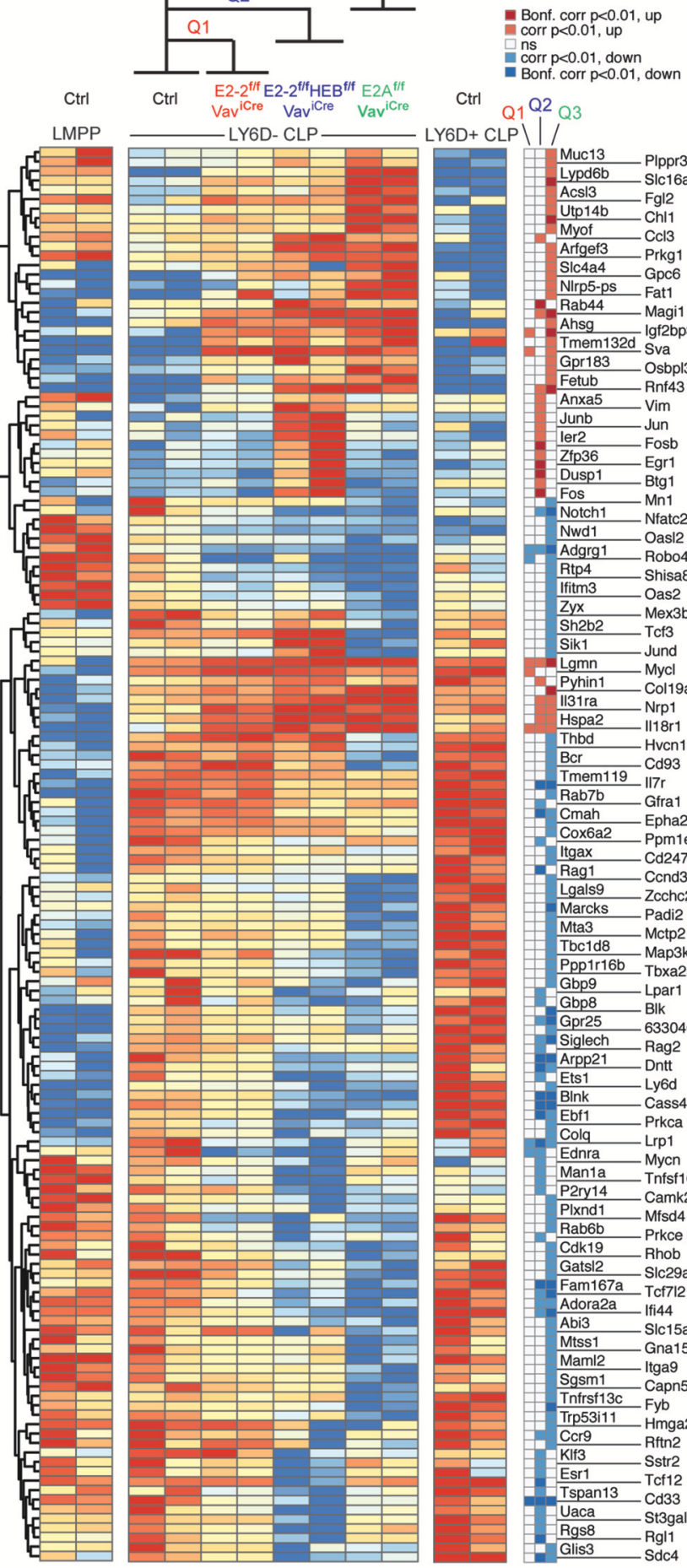

Ctrl Q1 Q2 Q3
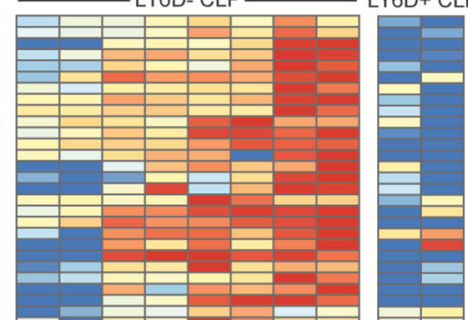

$P \backslash /{ }_{M u c 13}$

Muc13 Plppr3

\begin{tabular}{l}
$\frac{\text { Lypd6b }}{\text { Acsl3 }}$ Slc16a11 \\
\hline Utp14b \\
Cgl2
\end{tabular}

\begin{tabular}{ll} 
Utp14b & Chl1 \\
\hline Myof & Ccl3
\end{tabular}

\begin{tabular}{ll} 
Arfgef3 & Prkg1 \\
\hline Slc4a4 & Gpc6
\end{tabular}

$\frac{\text { Sic4a4 }}{\text { Nirp5-ps }}$ Gat1

Ahsg Magi1

Tmem132d Svi2bp

\begin{tabular}{ll} 
Gpr183 & Osbpl3 \\
\hline Fetub & Rnf43
\end{tabular}
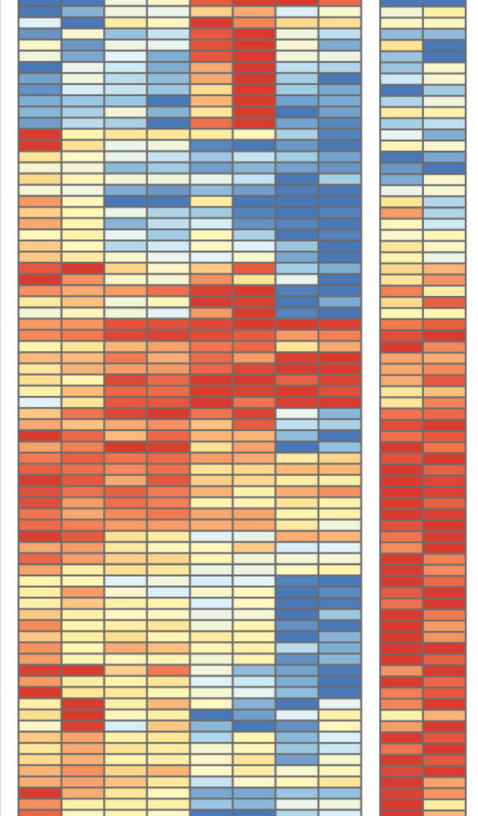

Anxa5 Vim

Junb Jun

Fosb

Dusp1 - Btg1

\begin{tabular}{ll} 
Fos & Mn1 \\
\hline Notch1 & Nfatc2
\end{tabular}

Nwd1 Oasl2

Adgrg1 Robo4

$\begin{array}{ll}\text { Rtp4 } & \text { Robo4 } \\ \text { Shisa8 }\end{array}$

Ifitm3 Oas2

\begin{tabular}{l}
$\frac{2 y x}{\text { Sh2b2 }}$ Mex3b $^{\text {Tcf3 }}$ \\
\hline Sik1 \\
\hline Jand
\end{tabular}

$=\frac{\text { Lyhin1 }}{\text { Pycl }}$ Col19a1

Il3tra Nrp1

Thbd H18r1

Bcr $\mathrm{Cd}$ Tmem119

Rab7b IIr $117 \mathrm{r}$

Cmah Epha2

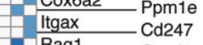

\begin{tabular}{ll} 
Rag1 & Ccnd3 \\
\hline Lgals9 & Zcchc24
\end{tabular}

Marcks - Padi2

Mta3 Mctp2

$\frac{\text { Tbc1d8 }}{\text { Ppp1r16b Map3k19 }}$

Gbp9 Lpar1

Gbp8 - Blk

Siglech 63304

Arpp21 Rntt

Ets1 Ly6d
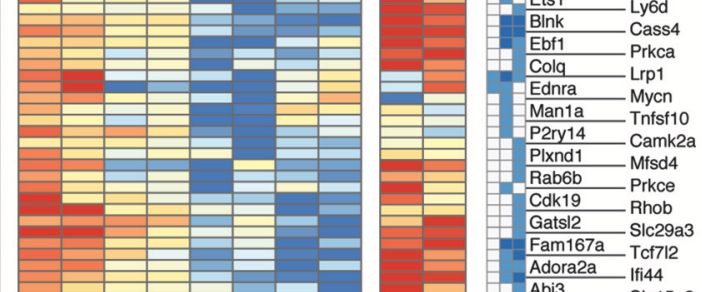

Ednra Lrp1

Man1a - Tnfsf10

P2ry14 Camk2a

Plxnd1 Mfsd4

Rab6b Prkce

Cdk19 Rhob

Gatsl2 SIc29a3

Fam167a Tcf7

\begin{tabular}{ll}
\hline Adora2a & Ifi44 \\
\hline Abi3 & Slc15a2
\end{tabular}

Mam12 Gna15

Maml2 Itga9

Tnfrsf13c Capn

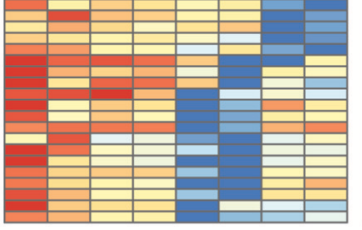

$\begin{array}{llllllllll}0 & 0.2 & 0.4 & 0.6 & 0.8 & 1.0\end{array}$

Trp53i11 - Hmga2

- Ccr9 Rftn2

Klf3
Esr1 Sstr2

Tspan13 Tcf12

Uaca St3gal6

Rgs8 Rgl1

FIGURE 5 | Loss of E-protein activity disrupts the early lymphoid transcriptional program. (A) Principal component analysis of RNAseq data. (B) Hierarchically clustered heatmap showing the (row normalized) expression of genes with significant (adjusted $p$-value $<0.01$ calculated by EdgeR) changes in LY6D-CLPs from $\mathrm{E} 2-2^{f / f} \operatorname{Vav}^{\mathrm{Cre}}(\mathrm{Q} 1), \mathrm{E} 2-2^{f / f} \mathrm{HEB}^{\mathrm{f} / \mathrm{f}} \operatorname{Vav}^{\mathrm{Cre}}(\mathrm{Q} 2)$ or E2A ${ }^{\mathrm{f} / f} \operatorname{Vav}^{\mathrm{Cre}}(\mathrm{Q} 3)$ as compared to control (ctrl). Significance of expression changes in each comparison (Q1-3) is indicated to the right of the heatmap. (C) Venn diagrams showing the overlap between the significant expression changes in the indicated genotypes. Relative expression change (mean expression is set to one for each gene) of up-regulated (D) and down-regulated genes (E) from Q1-Q3. *indicates a $p$-value $<0.002$ calculated using the Mann-Whitney $\cup$ test. 


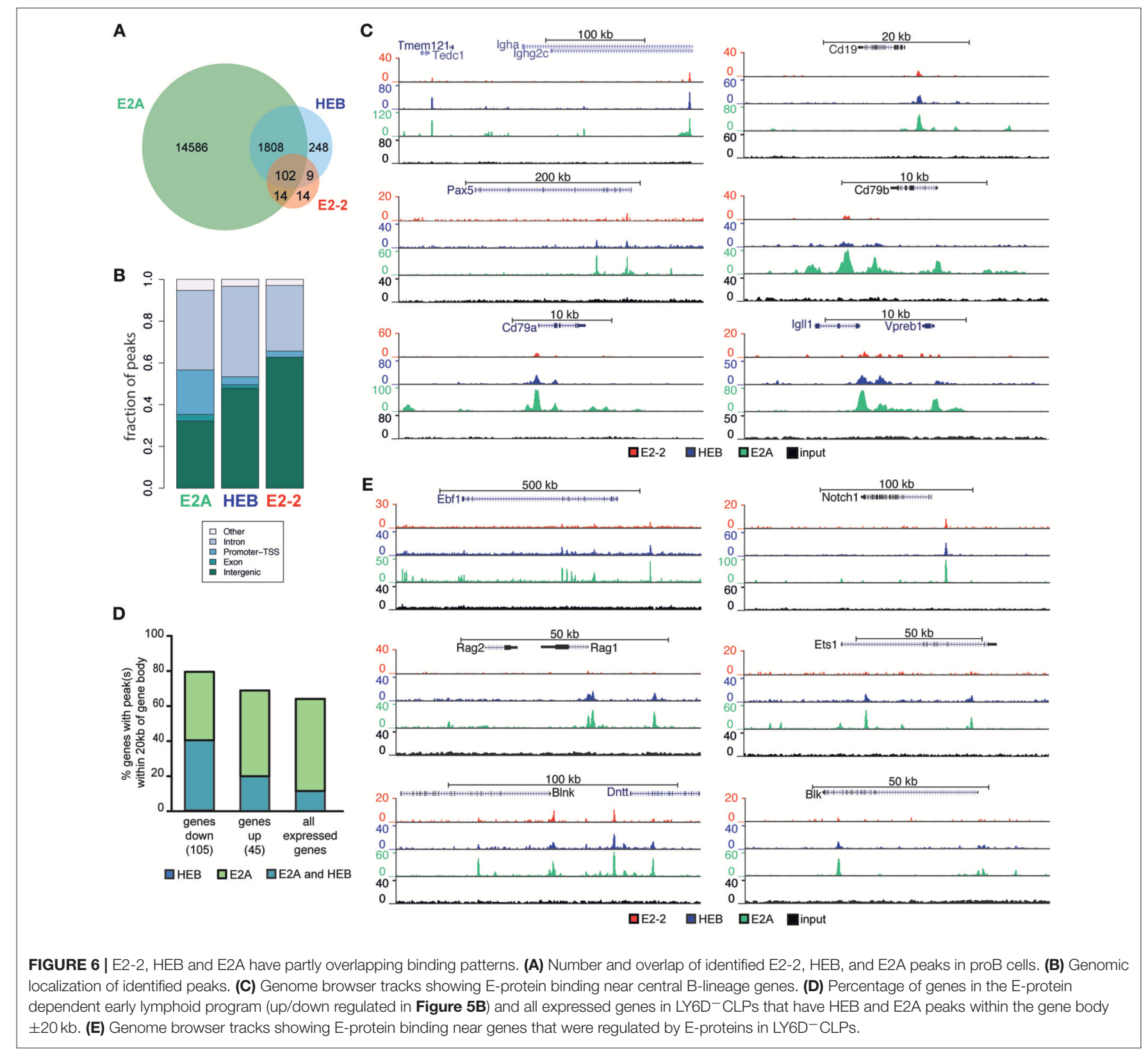

Figure S5A) limits accurate peak calling. Hence, E2-2 binding is likely underestimated. Peaks from the three E-protein ChIP experiments displayed highly significant enrichment of E-protein DNA binding motifs (Figure S5B).

E2A mostly bound regions without identified HEB and E22 peaks (Figure 6A, Figure S5C) while the majority of E22 and HEB peaks overlapped with E2A peaks (Figure 6A, Figure S5C). Interestingly while rare, sites with clearly biased Eprotein binding could be identified (Figure S5C). Most binding sites identified where localized in intronic and intergenic regions (Figure 6B). In contrast to the other E-proteins, a significant fraction of E2A peaks were also found in promoter regions (Figure 6B). No difference was observed in the Eprotein DNA binding motifs of HEB and/or E2A, with the most enriched motifs containing the same bHLH motif core (CAGCTG) (68). The most enriched motif in E2A peaks was present amongst the motifs found in the peaks common to E2A and HEB (Figure S5D). Genes central to B-lineage, including IgH, CD19, Pax5, CD79a, CD79b, Igll1, and VpreB, were bound by the three E-proteins (Figure 6C). A similar pattern was found for genes that are part of the E-proteindependent early lymphoid program in LY6D- CLPs (Figure 5B), including Ebf1, Rag1, Rag2, Blnk, Dntt, Notch1, and Blk (Figures 6D,E, Figure S5E). These regions at the center of the lymphoid and B-lineage programs, bound by E2A and HEB, presented a higher enrichment for Ebf and Pax DNA binding motifs compared to regions with only detectable E2A peaks (Figure S5F). 
Taken together this further supports the notion that E2-2 and HEB critically reinforce the action of E2A on gene regulatory circuits critical to early lymphoid specification and B-cell development.

\section{DISCUSSION}

Phylogenetic analysis of the E-proteins suggests that the Gnathostomata E-protein family arose through two subsequent duplications $(29,58)$. Interestingly, analysis of the structure of the E-protein loci in non-Gnathostomata argues for the original Gnathostomata E-protein being structurally similar to the present HEB/E2-2 loci (58). The initial duplication generated two Eprotein loci that diverged into the proto-E2-2/HEB and E2A loci. The second duplication subsequently gave rise to the E2-2 and HEB loci as well as two E2A loci out of which one was eventually lost $(58,69)$. Being evolutionarily related, E2-2 and HEB could hence support similar functions. The E-proteins play critical roles in all the hematopoietic lineages $(31,32,36,38,40-46,59-$ $61,70,71)$. However, the function of E2-2 in early hematopoietic development and its concerted action with the evolutionarily related E-protein HEB has not been thoroughly addressed.

The B-cell developmental pathway has been shown to critically rely on E2A and HEB, both TFs needed for the generation of $\mathrm{LY}^{+} \mathrm{D}^{+}$CLPs (32). We similarly found that the loss of E2-2 impaired the generation of LY6D ${ }^{+}$CLPs while earlier progenitors (including LMPPs and LY6D ${ }^{-}$CLPs) were unaffected. Further development of B-cells from LY6D ${ }^{+}$CLPs was unperturbed with the subsequent stages appearing at expected ratios. This indicates that the reduced number of B-cells is primarily caused by the impaired $\mathrm{LY}^{-} \mathrm{D}^{-}$to $\mathrm{LY} \mathrm{D}^{+}$transition within the CLP compartment.

Interestingly, the combined deletion of E2-2 and HEB had a direct additive effect resulting in a near complete developmental block at the $\mathrm{LY}^{-} \mathrm{D}^{-} \mathrm{CLP}$ stage and dramatically reduced Bcell numbers. Hence, E2-2 and HEB together have a critical and previously unrecognized role in supporting early lymphoid development in the BM. This phenotype is reminiscent of the one observed in E2A knockout animals (32). In line with this, the genes of the early lymphoid program were associated with combined E2A and HEB binding. This further supports the notion that all three E-proteins, to a large extent, reinforce the same gene regulatory circuit in CLPs (32).

The dramatic reduction of BM B-lymphopoiesis in E2$2^{\mathrm{ff}} \mathrm{Vav}^{\mathrm{iCre}}$ and $\mathrm{E} 2-2^{\mathrm{ff}} \mathrm{HEB}^{\mathrm{ff}} \mathrm{Vav}{ }^{\mathrm{iCre}}$ animals was mirrored in reduced numbers of transitional (T1 and T2) B-cells and reduced FoBs. In contrast MZ B-cell numbers were maintained in E2$2^{\mathrm{ff}} \mathrm{Vav}^{\mathrm{iCre}}$ mice or even expanded in $\mathrm{E} 2-2^{\mathrm{ff}} \mathrm{HEB}^{\mathrm{ff}} \mathrm{Vav}^{\mathrm{iCre}}$ mice. This, arguing that MZ B-cells are generated at the expense of FoBs, confirming that the levels of all three E-proteins are critical to maintain a normal $\mathrm{MZ}$ to FoB ratio $[60,61]$.

E2-2 ${ }^{\mathrm{ff}} \mathrm{Vav}^{\mathrm{iCre}}$ and $\mathrm{E} 2-2^{\mathrm{ff}} \mathrm{HEB}^{\mathrm{ff}} \mathrm{Vav}^{\mathrm{iCre}}$ mice displayed, on average, a $60 \%$ reduction in ETPs. Hence, while at a reduced level, E2A alone is sufficient to maintain thymic seeding in the absence of the other E-proteins $(38,45)$. T-cell development downstream of the ETP was significantly perturbed only in E2${ }^{\mathrm{ff}} \mathrm{HEB}^{\mathrm{ff}} \mathrm{Vav}^{\mathrm{iCre}}$ animals resulting in reduced CD4 T-cells and increased generation of $\gamma \delta$ T-cells. This phenotype is similar to the one observed in the HEB KO mice (36). Hence, this suggests that E2-2 has limited impact on adult thymopoiesis (59).

In line with previous findings, the number of pDCs was greatly reduced in mice lacking E2-2 (59, 72-74). However, we only observed a block in pDCs generation after the additional deletion of HEB (E2-2 $\left.{ }^{\mathrm{ff}} \mathrm{HEB}^{\mathrm{ff}} \mathrm{Vav}^{\mathrm{iCre}}\right)$. Hence, while E2-2 is clearly the main E-protein needed for $\mathrm{pDC}$ development, this indicates that $\mathrm{HEB}$ to a limited extent can support $\mathrm{pDC}$ development and cooperate with E2-2 in the pDC lineage.

In contrast to the clear impact of E2-2 and HEB on cells involved in humoral immunity (B- and CD4 T-cells), the loss of these TFs did not affect HSC numbers, erythro-myeloid progenitors nor the production of the major innate immune cells lineages including granulocytes, macrophages, and natural killer cells. Similarly the cytotoxic branch of adaptive immunity (CD8 T-cells) was unaffected.

Taken together, this suggests that E2-2 and HEB - in contrast to E2A (31,33-35) - are dispensable for lineages with ancestral functions. Functionally, this suggests that E2A, while structurally being the most divergent E-protein locus (58), maintains ancestral hematopoietic functions in addition to having been co-opted for lymphoid development and B-cell development in particular.

Until recently, it was hypothesized that the adaptive immune system arose from an evolutionary "big bang" at the speciation of the Gnathostomata (1). However, advances in genome sequencing of lower Deuterostomata has shifted this dogma by describing the presence of adaptive immunity related genes (including RAG, histocompatibility genes and immune type receptors) previously thought to be restricted to the Gnathostomata (20-25, 63). The presence of lymphoid-like cells in lower chordates (17-19) further suggests that the lymphoid genetic toolbox was present before the emergence of humoral immunity. Accordingly, the E-protein dependence of the early lymphoid program suggest that the appearance of the full Gnathostomata E-protein repertoire was crucial for reinforcing the gene regulatory circuits that drove the emergence and expansion of the hematopoietic lineages constituting humoral immunity.

\section{DATA AVAILABILITY}

Raw sequencing data are available from the European Nucleotide Archive (ENA) under accession number PRJEB29568 (E-protein knock-out RNAseq and E-protein ChIPseq) and PRJEB20316 (wild-type C57bl/6 RNAseq data).

\section{AUTHOR CONTRIBUTIONS}

TB, CG, and RM: planned the study; TB, SK, XL, AK, MH, CG, KS, and RM: performed the experiments; TB, LP-P, SK, XL, MH, $\mathrm{AD}, \mathrm{CG}, \mathrm{KS}$, and RM: analyzed the data; $\mathrm{CS}$ and $\mathrm{DH}$ : provided critical insights; CS and RM: supervised the research; TB, LP-P, $\mathrm{CG}$, and RM: wrote the manuscript. All authors reviewed the manuscript before submission. 


\section{ACKNOWLEDGMENTS}

We thank Prof. Joakim Dillner and colleagues (Karolinska Institutet) for access to the NextSeq 500 system; Associate Prof. Anders S. Nilsson (Stockholm University) for critical input on the phylogenetic analysis; Karolinska High Throughput Center (KHTC, Karolinska Institutet) for assistance with highthroughput sequencing; the preclinical laboratory at Karolinska University Hospital for access to their facilities; and UPPMAX Next Generation Sequencing Cluster \& Storage (UPPNEX) for computational resources. This work was funded by the Swedish

\section{REFERENCES}

1. Flajnik MF, Kasahara M. Origin and evolution of the adaptive immune system: genetic events and selective pressures. Nat Rev Genet. (2010) 11:47-59. doi: $10.1038 / \mathrm{nrg} 2703$

2. Litman GW, Rast JP, Fugmann SD. The origins of vertebrate adaptive immunity. Nat Rev Immunol. (2010) 10:543-53. doi: 10.1038/nri2807

3. Parra D, Takizawa F, Sunyer JO. Evolution of B cell immunity. Ann Rev Anim Biosci. (2013) 1:65-97. doi: 10.1146/annurev-animal-031412-103651

4. Azevedo Portilho N, Kobayashi M, Yoshimoto M. What do the lineage tracing studies tell us? Consideration for hematopoietic stem cell origin, dynamics, and leukemia-initiating cells. Int J Hematol. (2018) 109:35-40. doi: 10.1007/s12185-018-2537-9

5. Adolfsson J, Månsson R, Buza-Vidas N, Hultquist A, Liuba K, Jensen CT, et al. Identification of Flt3 ${ }^{+}$lympho-myeloid stem cells lacking erythromegakaryocytic potential: a revised road map for adult blood lineage commitment. Cell. (2005) 121:295-306. doi: 10.1016/j.cell.2005.02.013

6. Månsson R, Hultquist A, Luc S, Yang L, Anderson K, Kharazi S, et al. Molecular evidence for hierarchical transcriptional lineage priming in fetal and adult stem cells and multipotent progenitors. Immunity. (2007) 26:40719. doi: 10.1016/j.immuni.2007.02.013

7. Kondo M, Weissman IL, Akashi K. Identification of clonogenic common lymphoid progenitors in mouse bone marrow. Cell. (1997) 91:661-72. doi: 10.1016/S0092-8674(00)80453-5

8. Inlay MA, Bhattacharya D, Sahoo D, Serwold T, Seita J, Karsunky H, et al. Ly6d marks the earliest stage of B-cell specification and identifies the branchpoint between B-cell and T-cell development. Genes Dev. (2009) 23:2376-81. doi: 10.1101/gad.1836009

9. Mansson R, Zandi S, Welinder E, Tsapogas P, Sakaguchi N, Bryder D, et al. Single-cell analysis of the common lymphoid progenitor compartment reveals functional and molecular heterogeneity. Blood. (2010) 115:2601-9. doi: 10.1182/blood-2009-08-236398

10. Mansson R, Welinder E, Åhsberg J, Lin YC, Benner C, Glass CK, et al. Positive intergenic feedback circuitry, involving EBF1 and FOXO1, orchestrates B-cell fate. Proc Natl Acad Sci USA. (2012) 109:21028-33. doi: 10.1073/pnas.1211427109

11. Zlotoff DA, Bhandoola A. Hematopoietic progenitor migration to the adult thymus. Ann N Y Acad Sci. (2011) 1217:122-38. doi: 10.1111/j.1749-6632.2010.05881.x

12. Akashi K, Traver D, Miyamoto T, Weissman IL. A clonogenic common myeloid progenitor that gives rise to all myeloid lineages. Nature. (2000) 404:193-7. doi: 10.1038/35004599

13. Pronk CJH, Bryder D. Flow Cytometry-Based Identification of Immature Myeloerythroid Development. In: Hawley TS, Hawley RG, editors. Flow Cytometry Protocols. Totowa, NJ: Humana Press (2011). p. 275-93. doi: 10.1007/978-1-61737-950-5_13

14. Manz MG, Traver D, Miyamoto T, Weissman IL, Akashi K. Dendritic cell potentials of early lymphoid and myeloid progenitors. Blood. (2001) 97:333341. doi: 10.1182/blood.V97.11.3333

15. Nappi AJ, Ottaviani E. Cytotoxicity and cytotoxic molecules in invertebrates. BioEssays. (2000) 22:469-80. doi: 10.1002/(SICI)15211878(200005)22:5<469::AID-BIES9>3.0.CO;2-4
Cancer Foundation (Cancerfonden), the Swedish Research Council (VR), the Knut and Alice Wallenberg Foundation (KAW), the Swedish Foundation for Strategic Research (SSF), the European Commission (FP7 PIRG08-GA-2010-276906) and a generous donation by Björn and Lena Ulvaeus.

\section{SUPPLEMENTARY MATERIAL}

The Supplementary Material for this article can be found online at: https://www.frontiersin.org/articles/10.3389/fimmu. 2019.00455/full\#supplementary-material

16. Svoboda O, Bartunek P. Origins of the vertebrate erythro/megakaryocytic system. BioMed Res Int. (2015) 2015:10. doi: 10.1155/2015/632171

17. Suzuki T, Shin-I T, Kohara Y, Kasahara M. Transcriptome analysis of hagfish leukocytes: a framework for understanding the immune system of jawless fishes. Dev Comp Immunol. (2004) 28:993-1003. doi: 10.1016/j.dci.2004.04.005

18. Peddie CM, Smith VJ. 'Lymphocyte-like'cells in ascidians: precursors for vertebrate lymphocytes? Fish Shellf Immunol. (1995) 5:613-29.

19. Huang G, Xie X, Han Y, Fan L, Chen J, Mou C, et al. The identification of lymphocyte-like cells and lymphoid-related genes in amphioxus indicates the twilight for the emergency of adaptive immune system. PLoS ONE. (2007) 2:e206. doi: 10.1371/journal.pone.0000206

20. Kapitonov VV, Koonin EV. Evolution of the RAG1-RAG2 locus: both proteins came from the same transposon. Biol Direct. (2015) 10:20. doi: 10.1186/s13062-015-0055-8

21. Morales Poole JR, Huang SF, Xu A, Bayet J, Pontarotti P. The RAG transposon is active through the deuterostome evolution and domesticated in jawed vertebrates. Immunogenetics. (2017) 69:391-400. doi: 10.1007/s00251-017-0979-5

22. Azumi K, De Santis R, De Tomaso A, Rigoutsos I, Yoshizaki F, Pinto MR, et al. Genomic analysis of immunity in a Urochordate and the emergence of the vertebrate immune system: "waiting for Godot". Immunogenetics. (2003) 55:570-81. doi: 10.1007/s00251-003-0606-5

23. Voskoboynik A, Newman AM, Corey DM, Sahoo D, Pushkarev D, Neff NF, et al. Identification of a colonial chordate histocompatibility gene. Science. (2013) 341:384-7. doi: 10.1126/science.1238036

24. Du Pasquier L, Zucchetti I, De Santis R. Immunoglobulin superfamily receptors in protochordates: before RAG time. Immunol Rev. (2004) 198:23348. doi: 10.1111/j.0105-2896.2004.00122.x

25. Prada JAH, Haire RN, Allaire M, Jakoncic J, Stojanoff V, Cannon JP, et al. Ancient evolutionary origin of diversified variable regions demonstrated by crystal structures of an immune-type receptor in amphioxus. Nat Immunol. (2006) 7:875-82. doi: 10.1038/ni1359

26. Arendt D, Musser JM, Baker CVH, Bergman A, Cepko C, Erwin DH, et al. The origin and evolution of cell types. Nat Rev Genet. (2016) 17:744-57. doi: $10.1038 /$ nrg.2016.127

27. Simionato E, Ledent V, Richards G, Thomas-Chollier M, Kerner P, Coornaert $\mathrm{D}$, et al. Origin and diversification of the basic helix-loop-helix gene family in metazoans: insights from comparative genomics. BMC Evol Biol. (2007) 7:33. doi: 10.1186/1471-2148-7-33

28. Massari ME, Murre C. Helix-Loop-Helix proteins: regulators of transcription in eucaryotic organisms. Mol Cell Biol. (2000) 20:429-40. doi: 10.1128/MCB.20.2.429-440.2000

29. Shain DH, Neuman T, Zuber MX. Embryonic expression and evolution of duplicated E-protein genes in Xenopus laevis: parallels with ancestral E-protein genes. Genetics. (1997) 146:345-53.

30. Diez-Roux G, Banfi S, Sultan M, Geffers L, Anand S, Rozado D, et al. A high-resolution anatomical atlas of the transcriptome in the mouse embryo. PLoS Biol. (2011) 9:e1000582. doi: 10.1371/journal.pbio.10 00582

31. Semerad CL, Mercer EM, Inlay MA, Weissman IL, Murre C. E2A proteins maintain the hematopoietic stem cell pool and promote the maturation of 
myelolymphoid and myeloerythroid progenitors. Proc Natl Acad Sci USA. (2009) 106:1930-5. doi: 10.1073/pnas.0808866106

32. Welinder E, Mansson R, Mercer EM, Bryder D, Sigvardsson M, Murre C. The transcription factors E2A and HEB act in concert to induce the expression of FOXO1 in the common lymphoid progenitor. Proc Natl Acad Sci USA. (2011) 108:17402-7. doi: 10.1073/pnas.1111766108

33. Yang Q, Kardava L, St. Leger A, Martincic K, Varnum-Finney B, Bernstein ID, et al. E47 controls the developmental integrity and cell cycle quiescence of multipotential hematopoietic progenitors. J Immunol. (2008) 181:5885-94. doi: 10.4049/jimmunol.181.9.5885

34. Yang Q, Esplin B, Borghesi L. E47 regulates hematopoietic stem cell proliferation and energetics but not myeloid lineage restriction. Blood. (2011) 117:3529-38. doi: 10.1182/blood-2010-07-297689

35. Santos PM, Ding Y, Borghesi L. Cell-intrinsic in vivo requirement for the E47-p21 pathway in long-term hematopoietic stem cells. J Immunol. (2014) 192:160-8. doi: 10.4049/jimmunol.1302502

36. Barndt RJ, Dai M, Zhuang Y. Functions of E2A-HEB heterodimers in T-cell development revealed by a dominant negative mutation of HEB. Molecul Cell Biol. (2000) 20:6677-85. doi: 10.1128/MCB.20.18.6677-6685.2000

37. Beck K, Peak MM, Ota T, Nemazee D, Murre C. Distinct roles for E12 and E47 in $B$ cell specification and the sequential rearrangement of immunoglobulin light chain loci. J Exp Med. (2009) 206:2271-84. doi: 10.1084/jem.200 90756

38. Dias S, Månsson R, Gurbuxani S, Sigvardsson M, Kee BL. E2A proteins promote development of lymphoid-primed multipotent progenitors. Immunity. (2008) 29:217-27. doi: 10.1016/j.immuni.2008.05.015

39. Ikawa T, Kawamoto H, Goldrath AW, Murre C. E proteins and notch signaling cooperate to promote $\mathrm{T}$ cell lineage specification and commitment. J ExpMed. (2006) 203:1329-42. doi: 10.1084/jem.20060268

40. Kwon K, Hutter C, Sun Q, Bilic I, Cobaleda C, Malin S, et al. Instructive role of the transcription factor E2A in early B lymphopoiesis and germinal center B cell development. Immunity. (2008) 28:751-62. doi: 10.1016/j.immuni.2008.04.014

41. Lin YC, Jhunjhunwala S, Benner C, Heinz S, Welinder E, Mansson R, et al. A global network of transcription factors, involving E2A, EBF1 and Foxo1, that orchestrates B cell fate. Nat Immunol. (2010) 11:635-43. doi: 10.1038/ ni. 1891

42. Takeuchi A, Yamasaki S, Takase K, Nakatsu F, Arase H, Onodera $\mathrm{M}$, et al. E2A and HEB Activate the pre-TCR $\alpha$ promoter during immature $\mathrm{T}$ cell development. J Immunol. (2001) 167:2157-63. doi: 10.4049/jimmunol.167.4.2157

43. Wöhner M, Tagoh H, Bilic I, Jaritz M, Poliakova DK, Fischer M, et al. Molecular functions of the transcription factors E2A and E2-2 in controlling germinal center B cell and plasma cell development. J Exp Med. (2016) 213:1201-21. doi: 10.1084/jem.20152002

44. Wojciechowski J, Lai A, Kondo M, Zhuang Y. E2A and HEB are required to block thymocyte proliferation prior to pre-TCR expression. JImmunol. (2007) 178:5717-26. doi: 10.4049/jimmunol.178.9.5717

45. Xu W, Carr T, Ramirez K, McGregor S, Sigvardsson M, Kee BL. E2A transcription factors limit expression of Gata3 to facilitate $\mathrm{T}$ lymphocyte lineage commitment. Blood. (2013) 121:1534-42. doi: 10.1182/blood-2012-08-449447

46. Zhuang Y, Cheng P, Weintraub H. B-lymphocyte development is regulated by the combined dosage of three basic helix-loop-helix genes, E2A, E22, and HEB. Molecul Cell Biol. (1996) 16:2898-905. doi: 10.1128/MCB.16. 6.2898

47. Borghesi L, Aites J, Nelson S, Lefterov P, James P, Gerstein R. E47 is required for $\mathrm{V}(\mathrm{D}) \mathrm{J}$ recombinase activity in common lymphoid progenitors. J Exp Med. (2005) 202:1669-77. doi: 10.1084/jem.20051190

48. de Boer J, Williams A, Skavdis G, Harker N, Coles M, Tolaini M, et al. Transgenic mice with hematopoietic and lymphoid specific expression of Cre. Ear J Immunol. (2003) 33:314-25. doi: 10.1002/immu.200 310005

49. Bergqvist I, Eriksson M, Saarikettu J, Eriksson B, Corneliussen B, Grundström $\mathrm{T}$, et al. The basic helix-loop-helix transcription factor E2-2 is involved in T lymphocyte development. Eur J Immunol. (2000) 30:2857-63. doi: 10.1002/ 1521-4141(200010)30:10<2857::AID-IMMU2857>3.0.CO;2-G
50. Pan L, Hanrahan J, Li J, Hale LP, Zhuang Y. An analysis of T cell intrinsic roles of E2A by conditional gene disruption in the thymus. J Immunol. (2002) 168:3923-32. doi: 10.4049/jimmunol.168.8.3923

51. Zerbino DR, Achuthan P, Akanni W, Amode M R, Barrell D, Bhai J, et al. Ensembl 2018. Nucleic Acids Res. (2018) 46:D754-61. doi: 10.1093/nar/gkx1098

52. Kumar S, Stecher G, Tamura K. MEGA7: molecular evolutionary genetics analysis version 7.0 for bigger datasets. Molecul Biol Evol. (2016) 33:1870-4. doi: $10.1093 / \mathrm{molbev} / \mathrm{msw} 054$

53. Dobin A, Davis CA, Schlesinger F, Drenkow J, Zaleski C, Jha S, et al. STAR: ultrafast universal RNA-seq aligner. Bioinformatics. (2013) 29:15-21. doi: 10.1093/bioinformatics/bts635

54. Heinz S, Benner C, Spann N, Bertolino E, Lin YC, Laslo P, et al. Simple combinations of lineage-determining transcription factors prime cisregulatory elements required for macrophage and B cell identities. Molecul Cell. (2010) 38:576-89. doi: 10.1016/j.molcel.2010.05.004

55. Hayashi S, McMahon AP. Efficient recombination in diverse tissues by a tamoxifen-inducible form of Cre: a tool for temporally regulated gene activation/inactivation in the mouse. Dev Biol. (2002) 244:305-18. doi: 10.1006/dbio.2002.0597

56. Gustafsson C, De Paepe A, Schmidl C, Månsson R. High-throughput ChIPmentation: freely scalable, single day ChIPseq data generation from very low cell-numbers. BMC Genom. (2019) 20:59. doi: 10.1186/s12864-018-5299-0

57. Langmead B, Salzberg SL. Fast gapped-read alignment with Bowtie 2. Nature Methods. (2012) 9:357. doi: 10.1038/nmeth.1923

58. Schrankel CS, Solek CM, Buckley KM, Anderson MK, Rast JP. A conserved alternative form of the purple sea urchin HEB/E2-2/E2A transcription factor mediates a switch in E-protein regulatory state in differentiating immune cells. Dev Biol. (2016) 416:149-61. doi: 10.1016/j.ydbio.2016.05.034

59. Cisse B, Caton ML, Lehner M, Maeda T, Scheu S, Locksley R, et al. Transcription factor E2-2 is an essential and specific regulator of plasmacytoid dendritic cell development. Cell. (2008) 135:37-48. doi: 10.1016/j.cell.2008.09.016

60. Quong MW, Martensson A, Langerak AW, Rivera RR, Nemazee D, Murre C. Receptor editing and marginal zone B cell development are regulated by the helix-loop-helix protein, E2A. J Exp Med. (2004) 199:1101-12. doi: $10.1084 /$ jem. 20031180

61. Wikstrom I, Forssell J, Goncalves M, Colucci F, Holmberg D. E2-2 regulates the expansion of pro-B cells and follicular versus marginal zone decisions. $J$ Immunol. (2006) 177:6723-9. doi: 10.4049/jimmunol.177.10.6723

62. Han Y, Huang G, Zhang Q, Yuan S, Liu J, Zheng T, et al. The primitive immune system of amphioxus provides insights into the ancestral structure of the vertebrate immune system. Dev Compar Immunol. (2010) 34:791-6. doi: 10.1016/j.dci.2010.03.009

63. Kasahara M, Suzuki T, Pasquier LD. On the origins of the adaptive immune system: novel insights from invertebrates and cold-blooded vertebrates. Trends Immunol. (2004) 25:105-11. doi: 10.1016/j.it.2003.11.005

64. Meister M. Blood cells of drosophila: cell lineages and role in host defence. Curr Opin Immunol. (2004) 16:10-5. doi: 10.1016/j.coi.2003. 11.002

65. Pancer Z. Dynamic expression of multiple scavenger receptor cysteine-rich genes in coelomocytes of the purple sea urchin. Proc Natl Acad Sci USA. (2000) 97:13156-61. doi: 10.1073/pnas.230096397

66. Zhang B, Lin Y-Y, Dai M, Zhuang Y. Id3 and Id2 act as a dual safety mechanism in regulating the development and population size of innate-like $\gamma \delta$ T cells. J Immunol. (2014) 192:1055-63. doi: 10.4049/jimmunol.1302694

67. Schmidl C, Rendeiro AF, Sheffield NC, Bock C. ChIPmentation: fast, robust, low-input ChIP-seq for histones and transcription factors. Nat Methods. (2015) 12:963-5. doi: 10.1038/nmeth.3542

68. Schmitz R, Young RM, Ceribelli M, Jhavar S, Xiao W, Zhang M, et al. Burkitt lymphoma pathogenesis and therapeutic targets from structural and functional genomics. Nature. (2012) 490:116-20. doi: 10.1038/nature 11378

69. Hikima J-i, Cioffi CC, Middleton DL, Wilson MR, Miller NW, Clem LW, et al. Evolution of Transcriptional Control of the IgH Locus: characterization, expression, and function of TF12/HEB homologs of the catfish. J Immunol. (2004) 173:5476-84. doi: 10.4049/jimmunol.173.9.5476 
70. Ikawa T, Kawamoto H, Wright LYT, Murre C. Long-term cultured E2A-deficient hematopoietic progenitor cells are pluripotent. Immunity. (2004) 20:349-60. doi: 10.1016/S1074-7613(04) 00049-4

71. King AM, Keating P, Prabhu A, Blomberg BB, Riley RL. NK cells in the CD19- $\mathrm{B} 220+$ bone marrow fraction are increased in senescence and reduce E2A and surrogate light chain proteins in B cell precursors. Mech Ageing Dev. (2009) 130:384-92. doi: 10.1016/j.mad.2009. 03.002

72. Ghosh HS, Cisse B, Bunin A, Lewis KL, Reizis B. Continuous expression of the transcription factor E2-2 maintains the cell fate of mature plasmacytoid dendritic cells. Immunity. (2010) 33:905-16. doi: 10.1016/j.immuni.2010.11.023

73. Grajkowska LT, Ceribelli M, Lau CM, Warren ME, Tiniakou I, Nakandakari Higa S, et al. Isoform-specific expression and feedback regulation of E protein TCF4 control dendritic cell lineage specification. Immunity. (2017) 46:65-77. doi: 10.1016/j.immuni.2016.11.006
74. Nagasawa M, Schmidlin H, Hazekamp MG, Schotte R, Blom B. Development of human plasmacytoid dendritic cells depends on the combined action of the basic helix-loop-helix factor E2-2 and the Ets factor Spi-B. Eur J Immunol. (2008) 38:2389-400. doi: 10.1002/eji.200838470

Conflict of Interest Statement: The authors declare that the research was conducted in the absence of any commercial or financial relationships that could be construed as a potential conflict of interest.

Copyright (c) 2019 Bouderlique, Peña-Pérez, Kharazi, Hils, Li, Krstic, De Paepe, Schachtrup, Gustafsson, Holmberg, Schachtrup and Månsson. This is an open-access article distributed under the terms of the Creative Commons Attribution License (CC BY). The use, distribution or reproduction in other forums is permitted, provided the original author(s) and the copyright owner(s) are credited and that the original publication in this journal is cited, in accordance with accepted academic practice. No use, distribution or reproduction is permitted which does not comply with these terms. 